\title{
NORWOOD/BATISTA OPERATION FOR A NEWBORN WITH DILATED MYOPATHY OF THE LEFT VENTRICLE
}

Richard D. Mainwaring, MD, Regina M. Healy, BS, John D. Murphy, MD, and William I. Norwood, MD, PhD, Wilmington, Del

Partial left ventriculectomy for dilated cardiomyopathy was first reported by Batista and associates ${ }^{1}$ in 1996 . The rationale for this procedure is the increase in left ventricular cavity size in the absence of compensatory left ventricular wall thickness that is observed in dilated cardiomyopathy. This combination of factors results in an increase in wall stress per unit muscle mass, as predicted by the LaPlace equation. As wall stress increases, mechanical load eventually becomes nonsustainable and contributes to further dilation of the ventricle. Partial left ventriculectomy has been advocated as a method of restoring the balance between cavity size and wall thickness. Fundamental to this concept is the assumption that the left ventricular muscle is intrinsically normal or has recoverable

From Nemours Cardiac Center, Alfred I. duPont Hospital for Children, Wilmington, Del.

Received for publication Jan 18, 2000; accepted for publication Feb $18,2000$.

Address for reprints: Richard D. Mainwaring, MD, Nemours Cardiac Center, Alfred I. duPont Hospital for Children, PO Box 269, Wilmington, DE 19899 (E-mail: rmainwar@nemours.org).

J Thorac Cardiovasc Surg 2000;120:612-5

Copyright $\odot 2000$ by The American Association for Thoracic Surgery $0022-5223 / 2000 \$ 12.00+0 \quad \mathbf{1 2 / 5 4} / \mathbf{1 0 6 6 5 7}$

doi:10.1067/mtc.2000.106657 contractile function. The variable results that have been reported in the adult literature may reflect patient selection according to the reversibility or recoverability of the underlying disease process.

Despite the substantial worldwide experience with the Batista procedure in adult patients, there is limited experience with this procedure in children. The current case report describes the treatment of a patient in whom the diagnosis of dilated cardiomyopathy was made in utero.

Clinical summary. A female infant was recognized in utero as having a dilated, poorly functioning left ventricle. Labor was induced at 36 weeks' gestation, and she was delivered by normal, spontaneous, vaginal delivery. She underwent tracheal intubation in the delivery room because of poor tone and cyanosis. After her condition was stabilized, she was transferred to this institution.

A postnatal echocardiogram again revealed massive dilation of the left ventricle with severely depressed systolic function. There was mild mitral valve hypoplasia with severe insufficiency. The aortic valve anulus measured $7 \mathrm{~mm}$ in diameter, and the valve appeared normal. The aortic arch was unobstructed, but there was retrograde flow via the ductus into the transverse aortic arch. The right ventricular systolic function appeared to be normal. A chest film revealed marked cardiac enlargement with compression of the left lung. 

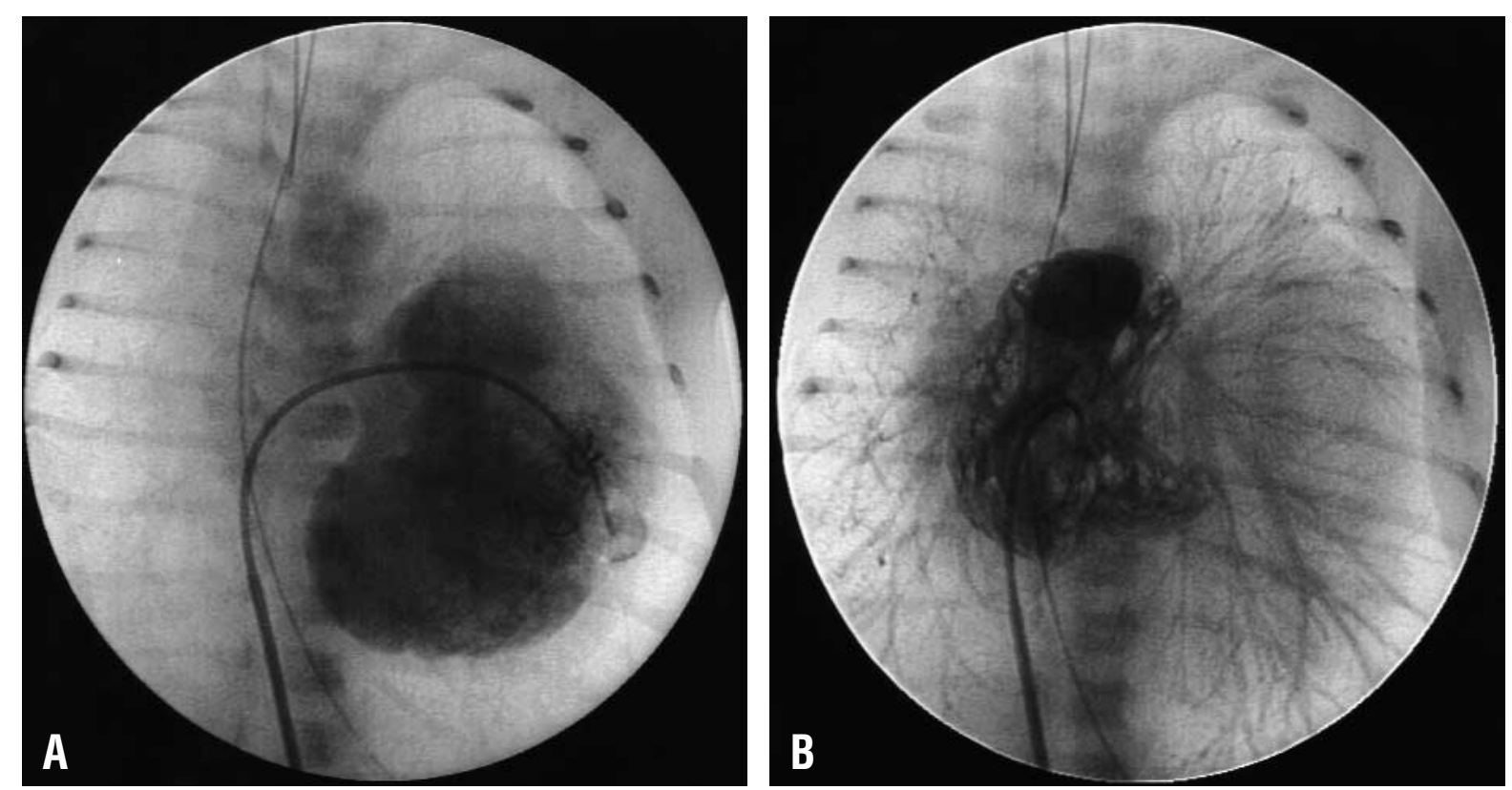

Fig 1. Left (A) and right (B) ventriculograms demonstrating unusual configuration of left ventricular cavity and the degree of dilation.

The patient was supported with a ventilator (inspired oxygen fraction of $0.21 \%$ ) and an intravenous infusion of alprostadil (prostaglandin $\mathrm{E}_{1}$ ). Cardiac catheterization demonstrated normal coronary artery connections and anatomy. A left ventriculogram confirmed the echocardiographic findings of a dilated left ventricle with poor function (Fig 1). The right and left ventricular end-diastolic pressures were 5 $\mathrm{mm} \mathrm{Hg}$ and $18 \mathrm{~mm} \mathrm{Hg}$, respectively.

At 5 days of age, the patient underwent a combined Norwood/Batista procedure. The Norwood portion of the procedure consisted of division of the main pulmonary artery and an end-to-side anastomosis of the proximal pulmonary artery to the ascending aorta. The distal opening in the branch pulmonary arteries was augmented with a homograft patch. An atrial septectomy was performed, and a 4-mm modified right Blalock-Taussig shunt was interposed between the innominate artery and the right branch pulmonary artery. The left ventricular cavity was opened, and gross inspection demonstrated a highly trabeculated endocardial surface. A cardiomyoplasty was performed by excising a portion of the left ventricular free wall (Fig 2). The total crossclamp time was 56 minutes. However, she could not be weaned from cardiopulmonary bypass because of significant hypotension. The patient was placed on extracorporeal circulatory support and transported to the cardiac intensive care unit.

Over the subsequent days, the patient had a stable cardiac rhythm and a gradual increase in aortic override. An initial attempt was made to wean her from extracorporeal support on the third postoperative day, but this failed because of progressive metabolic acidosis. The patient was successfully decannulated from extracorporeal support on the fifth post- operative day, and delayed sternal closure was performed on the sixth postoperative day.

The patient continued to have stable hemodynamics, but she did have an element of respiratory insufficiency. She was extubated successfully on the 20th postoperative day. Echocardiography revealed normal function of the right ventricle, essentially no function of the left ventricle, and mitral regurgitation that was graded as mild. A follow-up cardiac catheterization (Fig 3), performed on the 30th postoperative day, demonstrated that the right and left ventricular end-diastolic pressures were identical at $6 \mathrm{~mm} \mathrm{Hg}$. The patient was discharged from the hospital on the 53rd day after the operation.

Discussion. This case describes the early clinical course of a patient born with dilated myopathy of the left ventricle. On the basis of echocardiographic and cardiac catheterization data, we believed that the left ventricle would not support systemic perfusion. We therefore elected to use the right ventricle as the systemic pump by associating the proximal main pulmonary artery to the aorta. It was also our premise that the left ventricle was competing for space and impairing function of the normal right ventricle and left lung. Therefore, a reduction cardiomyoplasty was performed. In support of this premise, the end-diastolic pressure of the right ventricle was reduced at the follow-up cardiac catheterization and, radiographically, the left lung was able to expand more fully.

Two previous case reports have described the application of the Batista procedure in infants with dilated myopathy of the left ventricle. ${ }^{2,3}$ In these reports, the combination of reduction cardiomyoplasty and mitral valve repair was successful in permitting a biventricular repair. The histology of the left ventricular muscle demonstrated endomyocardial fibrous 


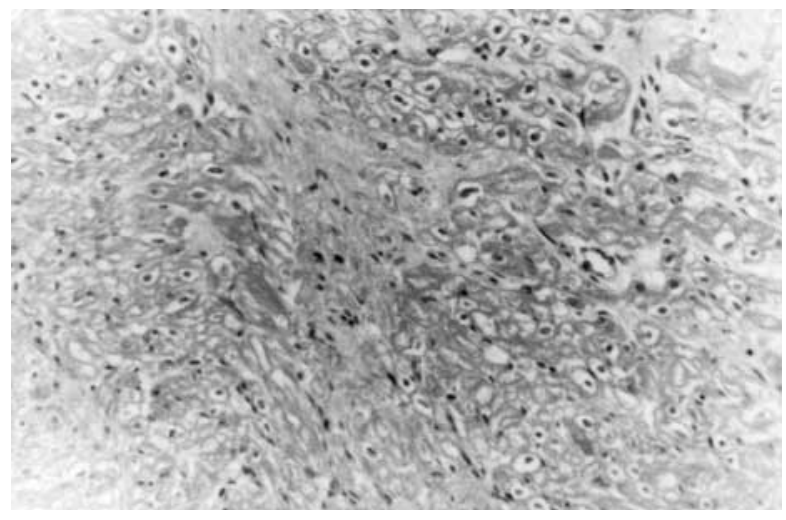

Fig 2. Photomicrograph of specimen demonstrating noncompaction of left ventricular muscle.

thickening in 1 patient and was indeterminate in the other. These 2 children have done well in follow-up, indicating that left ventricular function was recoverable. Since the fundamental assumption of the Batista procedure is that a portion of the left ventricular muscle must be intrinsically normal to permit recovery, one is led to conclude that the underlying disease in these 2 children either was a transient process $s^{4,5}$ or was relatively focal in nature. In an editorial review of these cases, del $\mathrm{Nido}^{6}$ suggested that spontaneous recovery may have been possible in 1 or both of these patients. This suggestion is based on the observation that a significant subset of these patients will improve with medical management as evidenced by the fact that the natural history of dilated cardiomyopathy at this age is unpredictable. ${ }^{7,8}$

In contrast to the 2 previous case reports, the chance of achieving recoverable function in the current case appears less likely. This patient had signs of dilated cardiomyopathy in utero. After delivery, the right ventricle continued to function as the systemic pump, as evidenced by retrograde flow in the aortic arch. Therefore, it is evident that this was not a transient phenomenon. Imaging of the left ventricle demonstrated global dysfunction, and the histology of the resected muscle showed a diffuse process of ventricular noncompaction. Noncompaction (or spongy myocardium) is a relatively rare developmental anomaly characterized by markedly irregular endocardial surfaces with prominent trabeculations and deep intertrabecular recesses. ${ }^{9}$ Noncompaction of the left ventricle is usually found in association with Barth syndrome, an $\mathrm{x}-$ linked disorder that also encompasses skeletal myopathy, short stature, and neutropenia. ${ }^{10}$ The patient described in our report had none of these associated features. Isolated noncompaction of the left ventricle also has been described but is even less common than cases associated with Barth syndrome. ${ }^{11}$ In either form of noncompaction, the infant mortality rate reported in the literature is extremely high because of failure of the myocardium. The majority of survivors are those in whom cardiac transplantation was performed. Because the disease process of noncompaction affects only the left ventricle, our approach was to bypass the left side of

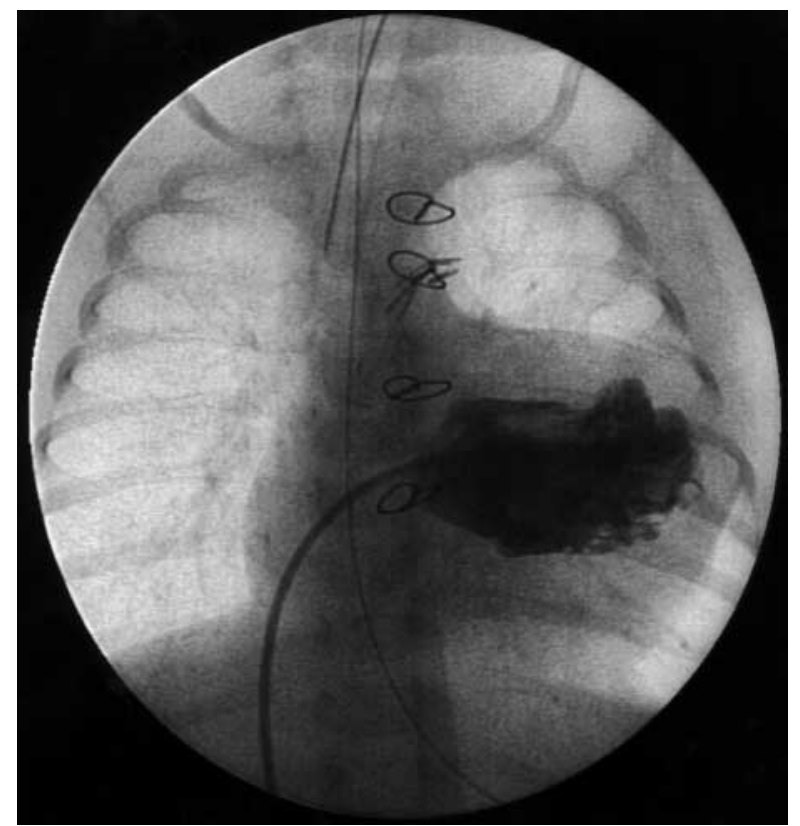

Fig 3. Left ventriculogram of the patient 30 days after reduction cardiomyoplasty. There is a marked reduction in left ventricular cavity size.

the heart by performing a Norwood procedure in conjunction with partial left ventriculectomy. We believe that this combined procedure has not been previously performed for this disease process or for any other.

This patient is now 6 months old and has demonstrated slow but steady weight gain. Cardiac catheterization, performed in anticipation of her hemi-Fontan procedure, revealed a persistently abnormal left ventricle with minimal mechanical function. The right ventricle had normal systolic properties with an end-diastolic pressure of $9 \mathrm{~mm} \mathrm{Hg}$. She subsequently underwent the hemi-Fontan procedure and had an uneventful postoperative course.

In summary, this case report documents our experience with a patient with isolated noncompaction of the left ventricle identified in utero. Our management approach was a combined Norwood/Batista procedure. The early success of this approach suggests that this may be applicable to other patients born with noncompaction of the left ventricle.

\section{REFERENCES}

1. Batista RJV, Santos JLV, Takeshita N, Bocchino L, Lima PN, Cunha MA. Partial left ventriculectomy to improve left ventricular function in end-stage heart disease. J Card Surg 1996;11:96-7.

2. Yoshii S, Hosaka S, Takahashi W, Amano H, Abraham SJK, Kaga $\mathrm{S}$, et al. Partial left ventriculectomy in an infant with dilated cardiomyopathy. J Thorac Cardiovasc Surg 1999;117:616-8.

3. Berger S, Tweddell JS, Frommelt PC, Weinhaus L. Partial left ventriculectomy for dilated cardiomyopathy in a newborn. J Thorac Cardiovasc Surg 1999;117:1017-8. 
4. Vaillant MC, Chantepie A, Chamboux C, Sue AL, Gold F, Laugier J. Transient hypertrophic cardiomyopathy in neonates after acute fetal distress. Pediatr Cardiol 1997;18:52-6.

5. Booker PD. Myocardial stunning in the neonate. Br J Anaesth 1998;80:371-83.

6. del Nido PJ. Editorial. Partial left ventriculectomy for dilated cardiomyopathy in children. $\mathbf{J}$ Thorac Cardiovasc Surg 1999;117:918-9.

7. Arola A, Tuominen J, Ruuskanen O, Jokinen E. Idiopathic dilated cardiomyopathy in children: prognostic indicators and outcome. Pediatrics 1998;101:369-76.

8. Burch M, Siddiqi SA, Celermajer DS, Scott C, Bull C, Deanfield
JE. Dilated cardiomyopathy in children: determinants of outcome. Br Heart J 1994;72:246-50.

9. Agmon Y, Connolly HM, Olson LJ, Khandheria BK, Seward JB. Noncompaction of the ventricular myocardium. J Am Soc Echocardiogr 1999;12:859-63.

10. Chin TK, Perloff JK, Williams RG, Jue K, Mohrmann R. Isolated noncompaction of the left ventricular myocardium: a study of eight cases. Circulation 1990;82:507-13.

11. Bleyl SB, Mumford BR, Thompson V, Carey JC, Pysher TJ, Chin TK, et al. Neonatal, lethal noncompaction of the left ventricular myocardium is allelic with Barth syndrome. Am J Hum Genet 1997;61:868-72 